\title{
THE ANTAGONISTIC ACTIVITY OF ACTINOMYCETES OF STREPTOMYCES GENUS IN RELATION TO TRICHODERMA KONINGII
}

\author{
Barbara Breza-Boruta' ${ }^{1}$ Z Zbigniew Paluszak ${ }^{1}$ \\ 1 Department of Microbiology and Food Technology, University of Science and Technology in Bydgoszcz, \\ Bernardyńska 6, 85-029 Bydgoszcz, Poland, e-mail: breza@utp.edu.pl
}

Received: 2015.11.08

Accepted: 2015.12.09

Published: 2016.01.06

\begin{abstract}
The aim of the study was to estimate the effect of actinomycetes of genus Streptomyces on the growth of the antagonistic fungus Trichoderma koningii. 150 strains of Streptomyces spp. isolated from two potato cropping systems were used to the tests. Analyses were conducted experimentally in vitro on PDA medium with $\mathrm{pH} 6$ and 7 . The results obtained clearly indicate the inhibitory effect of actinomycetes on the fungus T. koningii. Of the tested population of actinomycetes only two strains did not inhibit the growth of the tested fungus. The strains from the rhizosphere of potato cultivated under the ecological system were predominant in the group of actinomycetes with a very strong effect. $\mathrm{pH}$ value appeared to be a crucial factor influencing the inhibition zone. High antagonistic activity in relation to the useful fungus T. koningii noted with numerous strains of Streptomyces spp. is unfavorable in respect of biological control.
\end{abstract}

Keywords: antagonism, Streptomyces, Trichoderma koningii, soil, antifungal activity.

\section{INTRODUCTION}

The main problem connected with using microorganisms in biological control is their ability to survive in soil after introduction, and their effective action. There are many biological and physicochemical factors determining the survival of microorganisms introducing into soil. Of the biological factors, native bacteria, fungi, actinomycetes and their metabolites (antibiotics, mycotoxines, enzymes) are of great importance [Oskay 2009, Sharma et al. 2014].

Actinomycetes are the most known microorganisms with antagonistic properties in consideration of the synthesis of antibiotics. This most numerous group of antibiotic producers can protect plants against phytopathogens, which was noted in many field and laboratory experiments [Kumar et al. 2010, Evangelista-Martínez 2014, Kamal and Sharma 2014]. Antagonistic abilities of Streptomyces result also from producing extracellular enzymes causing the lysis of other microorganisms. They may parasitize on the hyphae of fungi, their oospores, or sclerotia [Prapagdee et al. 2008]. Mycoantagonistic properties of strains Streptomyces spp. were generally studied in relation to phytopathogenic fungi, e.g. Rhizoctonia solani, Fusarium solani, Phytophthora sp. [BrezaBoruta et al. 2004, Bressan and Figueiredo 2008, Al-Askar et al. 2011], while little is known about their effect on potentially antagonistic fungi.

The best known antagonists of microorganisms causing plant diseases among soil fungi are Trichoderma genus, and in particular, the species: T. viride, T. koningii, T. harzianum. The mechanism of their action consists in the ability to synthesize antibiotics and possibility of specific parasitizing on the fungal spawn of phytopathogens by excreting an active complex of enzymes [Howell 2003, Gajera et al. 2012, Reddy et al. 2014]. Several preparations were developed based on these fungi. However, it appears that their introduction into soil not always results in the effective reduction in pathogens [Świerczyńska et al. 2011]. The reason for this may be the action of other microorganisms with stronger antagonistic properties [Compant et al. 2005, Felice et al. 2014]. 
Therefore, the aim of the study was to find out the inhibition rate of actinomycetes of Streptomyces genus on the growth of Trichoderma koningii mycelium. In this study we compared the antagonistic activity of the strains of Streptomyces spp. isolated from two potato plantations with different farming systems, ecological and conventional. The effect of the medium $\mathrm{pH}$ on the growth of the fungal mycelium has also been tested.

\section{MATERIAL AND METHODS}

150 strains of actinomycetes of the genus Streptomyces isolated from potato crop were used for the study. "Aster" potato was cultivated in two farming systems, ecological and conventional, on lessive soils. Detailed characterization of the specifics concerning cultivation technologies applied in the compared farming systems was presented in the study by Breza-Boruta [2013]. 75 strains were isolated during growth periods from each farming system: 30 strains from soil beyond roots (ZEG - ecological farming and ZTG - conventional farming), 30 from rhizosphere (ZER - ecological farming and ZTR - conventional farming ) and 15 from potato rhizoplane (ZERp - ecological farming and ZTRp - conventional farming). Actinomycetes were isolated on the Williams and Davies selective medium [1965]. Diagnostic tests of actinomycetes strains were performed based on macro and microscopic features according to Bergey's Manual of Systematic Bacteriology [Goodfellow et al. 2012] and Crawford et al. [1993].

The tested fungus was the saprophytic species Trichoderma koningii, which had previously been examined for mycoparasitical abilities in relation to phytopathogenic fungi. T. koningii was isolated from the rhizosphere of potato cultivated on the ecological farm. Taxonomic determination of the fungus was made based on mycological keys, according to Domsch et al. [1980].

The method of two simultaneous cultures was used to estimate antagonistic features of investigated actinomycetes in relation to the tested fungus. Five-day-old cultures of Streptomyces spp. were used in the study. The cultures were inoculated with a line of $40 \mathrm{~mm}$ in length on potato dextrose agar (PDA, Merck). After 7 days' incubation, a 72-hour-old culture of T. koningii was added to each actinomycetes. The mycelium was placed in a form of circles of $8 \mathrm{~mm}$ in diameter. Control plates without actinomycetes were inocu- lated in the same way. The experiment was conducted with three replications on two media with $\mathrm{pH}$ values 6 and 7 .

The growth inhibition rate of $T$. koningii was estimated after 72 and 120 hours of incubation at $19-20^{\circ} \mathrm{C}$. The measure of inhibition rate was the difference between the radius of the fungal mycelium on the control plates with a given $\mathrm{pH}$ value and the radius of the fungal mycelium grown in the presence of actinomycetes, expressed in $\mathrm{mm}$.

The evaluation of antagonistic properties of tested population of Streptomyces spp. in relation to $T$. koningii was performed using the modified method of Lee and Hwang [2002]. The effect of strains was characterized on a scale of five degrees, where the length of inhibition zone of the fungal mycelium was estimated proportionally, in relation to the control:

- $0 \%$ - lack of effect,

- $1-25 \%$ - week effect

- $26-50 \%$ - moderate effect

- $51-75 \%$ - strong effect

- $76-100 \%$ - very strong effect.

The results were calculated statistically with the use of variance analysis. The differences of mean inhibition zones were evaluated based on Tukey's test $(\mathrm{p}=0.05)$ using Statistica 10.0 (StatSoft, Poland). The measurement of the fungal mycelium radius length after 5 days of cultivation was used for calculations.

\section{RESULTS}

The analyses showed strong antagonistic properties of the investigated population of actinomycetes in relation to the tested fungus. Only two strains of Streptomyces spp. (isolated from soil) did not inhibit the growth of $T$. koningii. The analysis with Student's t-test has shown a significant impact of $\mathrm{pH}$ value on the size of inhibition zones (Figures 1-3). In most cases, significantly larger zones were recorded on the medium with $\mathrm{pH} 6$ than on that with $\mathrm{pH} 7$.

Of actinomycetes isolated from soil, the strains derived from the ecological farming system proved to be slightly more active than those from the conventional farming (Figure 1). 27\% of strains from the ecological farming and 13\% from the conventional system were in the group of $T$. koningii very strongly inhibiting the fungal growth in the tests on the medium with $\mathrm{pH}$ 6. In the tests conducted on the medium with $\mathrm{pH} 7$, 


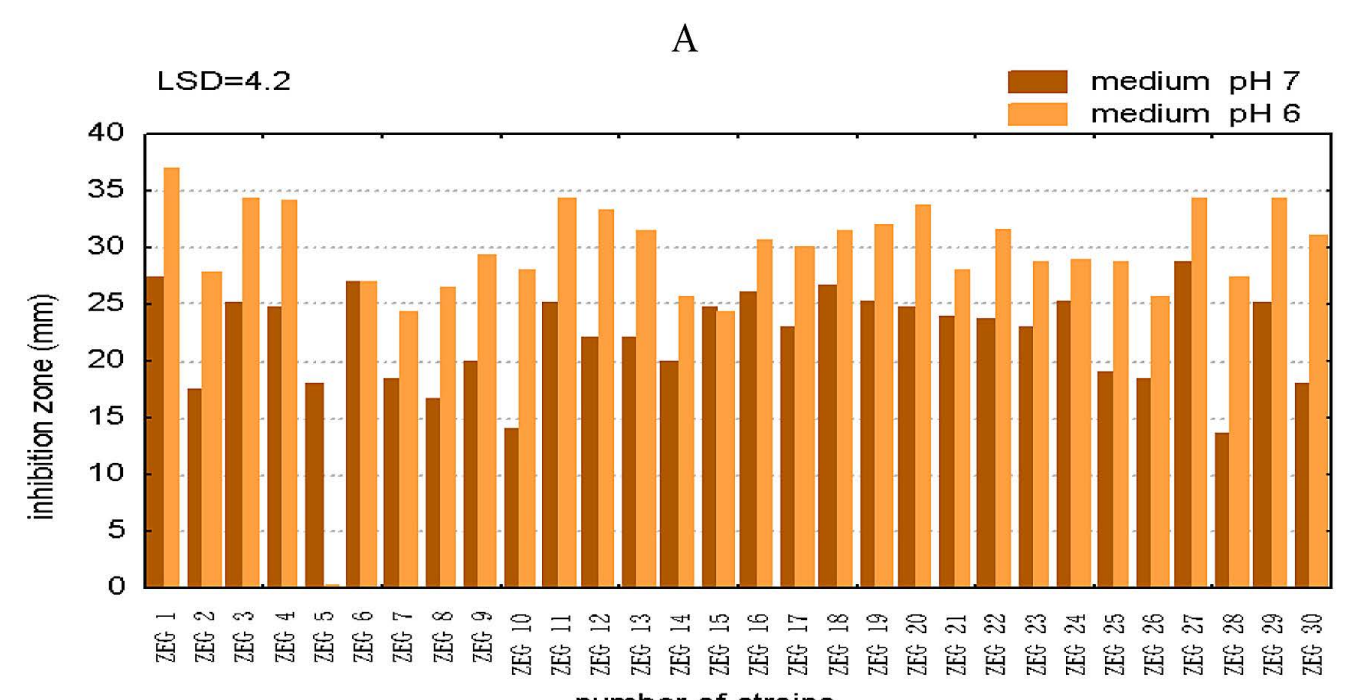

number of strains

B

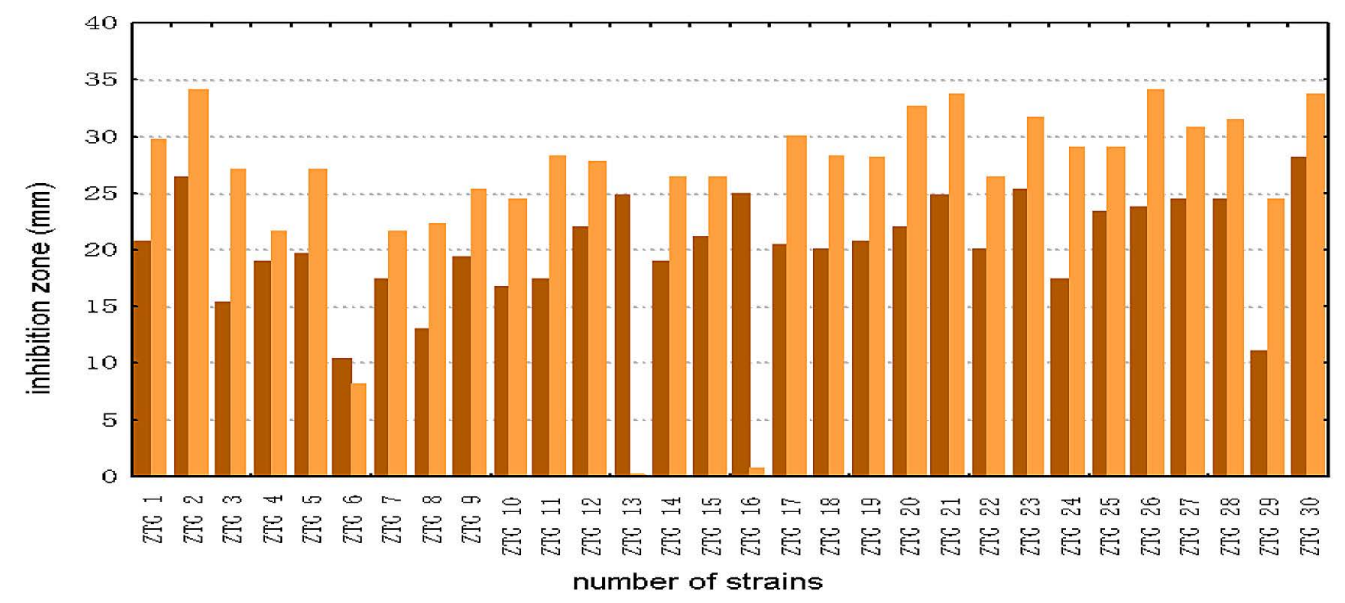

Figure 1. Influence of Streptomyces spp. strains isolated from non-rhizosphere soil of potato cultivated in ecological (A) and conventional (B) farming, on growth inhibition of T. koningii

$13 \%$ and $10 \%$ of isolates, respectively, showed very strong inhibitory effect. Most isolates from soil (77\%) strongly affected the growth of $T$. koningii. Only actinomycetes derived from the conventional farming system had a weak effect $-7 \%$ of strains tested on the medium with the lower $\mathrm{pH}$ value. Only $3 \%$ of strains, both from the conventional and ecological systems (on the medium with $\mathrm{pH}$ 6) showed the lack of inhibitory effect on the growth of $T$. koningii.

All the tested population of actinomycetes isolated from the rizosphere of potato cultivated under the ecological farming inhibited the growth of T. koningii (Figure 2). However, in the collection of Streptomyces spp. from the conventional system $10 \%$ of strains weakly inhibited the growth of the fungal mycelium were detected, but only on the medium with $\mathrm{pH} 6.7 \%$ of strains from both farming systems showed the moderate inhibitory effect. Very strong antagonism was detected in
$33 \%$ of tested strains tested on the medium with the lower $\mathrm{pH}$ value and in $53 \%$ of strains growing on the medium with the higher $\mathrm{pH}$ (Figure 4).

Isolates derived from the rhizoplane of potato were also characterized by strong mycoantagonistic properties (Figure 3).

Totally $73 \%$ of strains from the ecological farming and $87 \%$ of strains coming from the conventional farming grown on the medium with $\mathrm{pH}$ 6 , and $73 \%$ and $60 \%$, respectively, grown on the medium with $\mathrm{pH} 7$, which belong to the group strongly and very strongly inhibiting the growth of $T$. koningii. The other cultures of actinomycetes isolated from the surface of potato roots were marked by the moderate inhibitory activity (Figure 4).

Of the tested Streptomyces spp., the following strains showed the highest antagonistic activity against Trichoderma koningii: ZER-9 and ZER-29 - inhibiting the growth of the myce- 


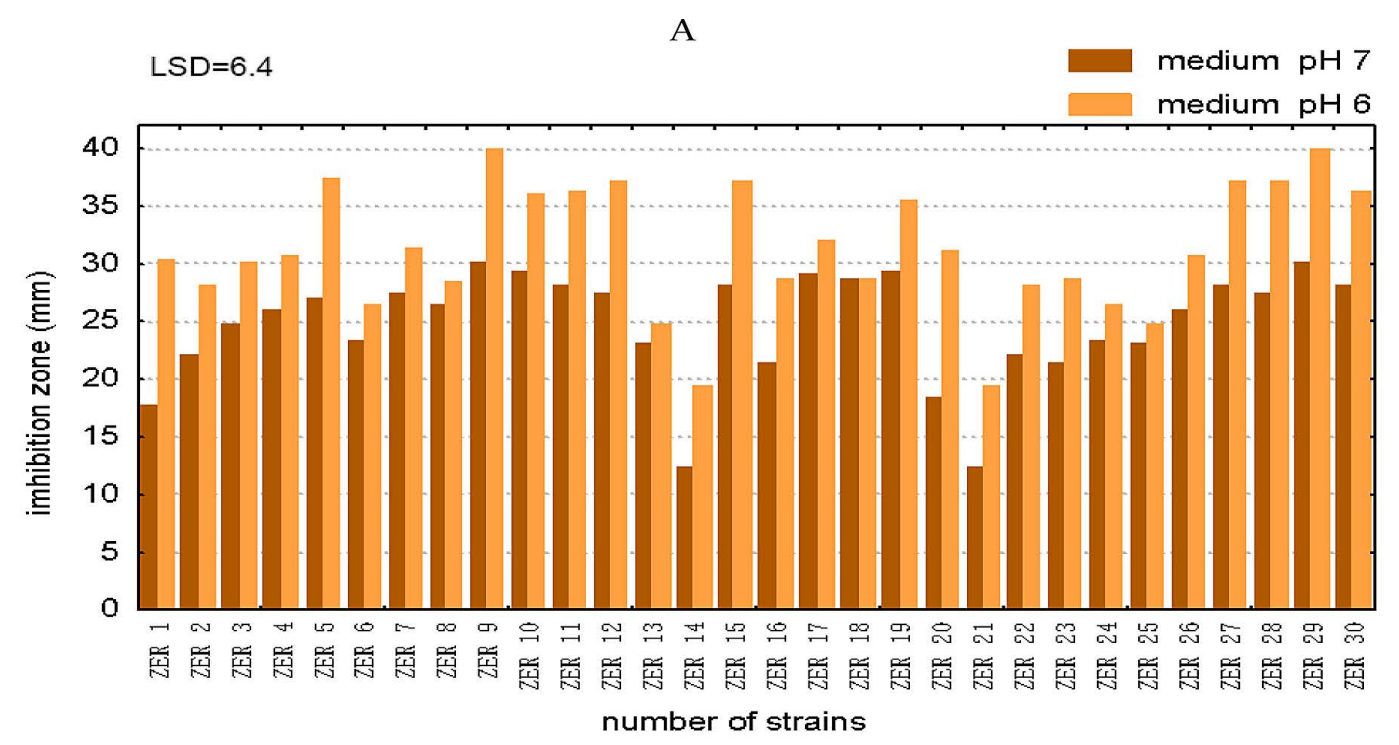

B

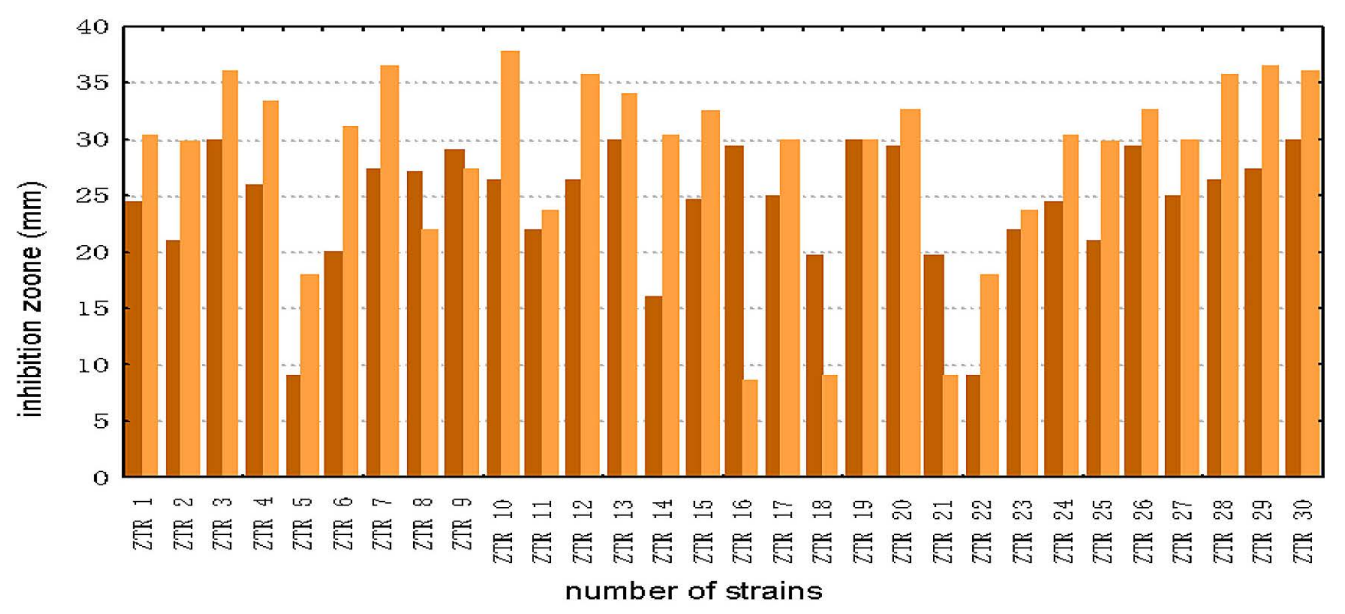

Figure 2. Influence of Streptomyces spp. strains isolated from rhizosphere of potato cultivated in ecological (A) and conventional (B) farming, on growth inhibition of T. koningii

lium to $40 \mathrm{~mm}$; ZEG-1, ZER-5, ZER-12, ZER15, ZER-27, ZER-28, ZTR-10 - inhibiting the growth to $37 \mathrm{~mm}$.

\section{DISCUSSION}

The present investigations indicate that actinomycetes can very actively inhibit the growth of useful fungi of the genus Trichoderma. The group of the most active actinomycetes very strongly inhibiting the growth of Trichoderma koningii included 50 of 150 strains tested. Oskay [2009] reports that fungi show much more resistance to antibiotics excreted by actinomycetes than bacteria. The presented results concerning the resistance of $T$. koningii do not confirm this. Their strong inhibitory properties could be observed also in other investigations on the antagonistic activity of actinomycetes in relation to the fungi Rhizoctonia solani [Breza-Boruta 2004].

The phenomena of antagonism, irrespective of the nature of their mechanism, regulate the coexistence of various species of microorganisms, both pathogens and saprophytes. Both the fungi of the genus Trichoderma and actinomycetes with the antagonistic effect are good competitors and producers of antibiotics and enzymes [Solecka et al. 2013, Reddy et al. 2014].

The results obtained in our studies indicated that actinomycetes of the genus Streptomyces showed stronger antagonistic properties in vitro in comparison with T. koningii. Only two tested isolates, one from the ecological system (the strain ZEG-5) and one from the conventional system (ZTG-13), did not show antagonistic properties. The visible growth of the fungal mycelium on the culture of actinomycetes took place in these two 


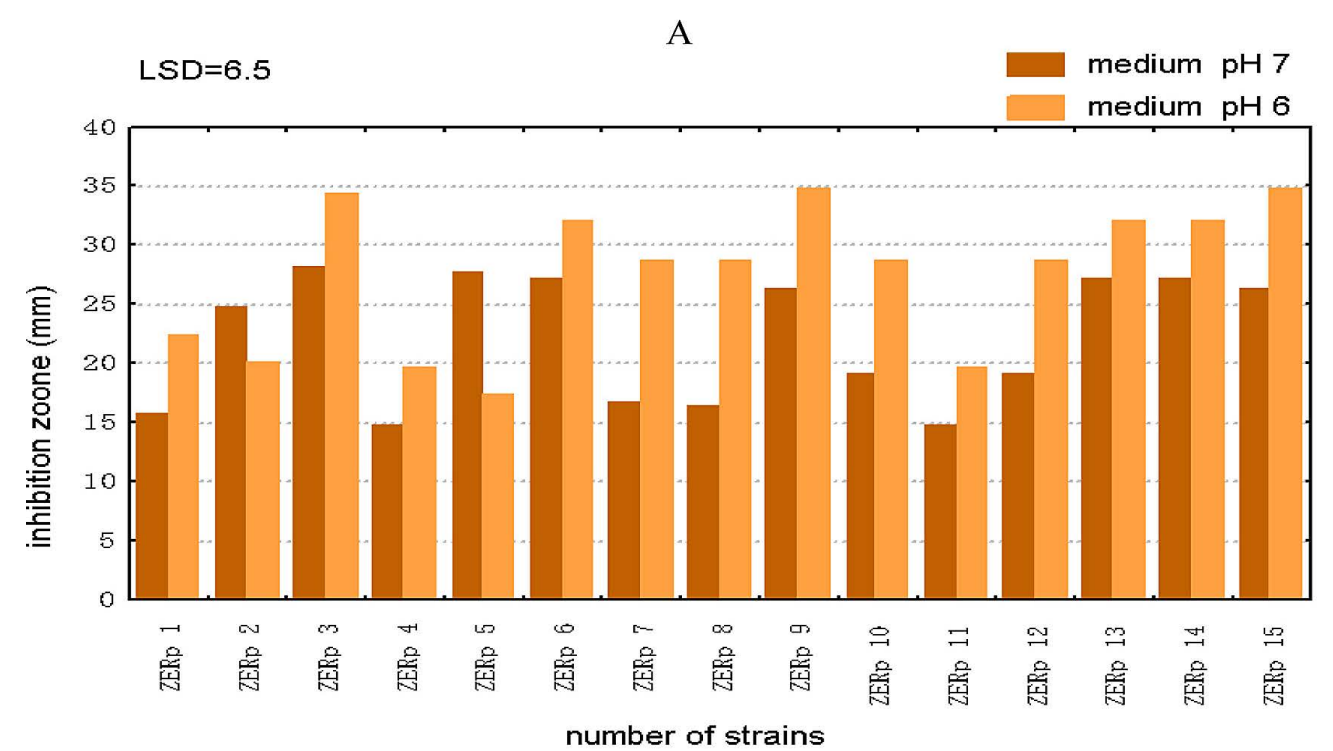

$\mathrm{B}$

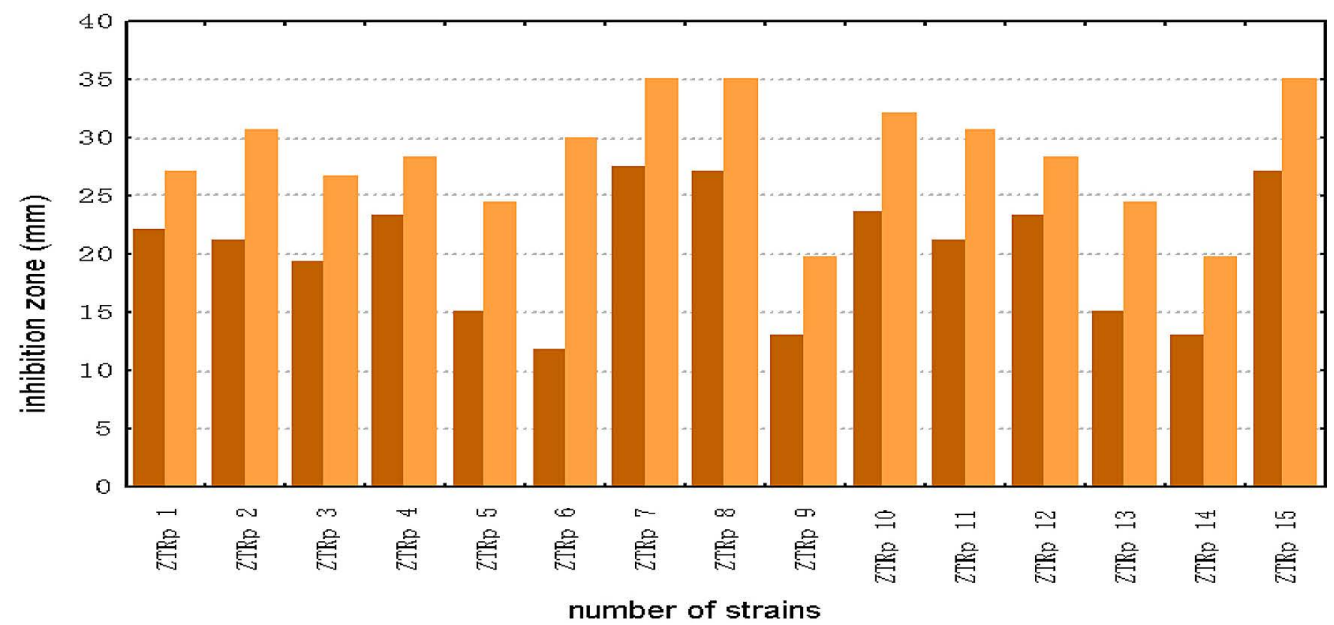

Figure 3. Influence of Streptomyces spp. strains isolated from rhizoplane of potato cultivated in ecological (A) and conventional (B) farming, on growth inhibition of T. koningii

cases. In opposition to mycoparasitizing, antibiosis is more effective in relation to metabolically active structures. In general, it does not require direct contact with a sensitive fungus and does not lead to destruction of its cells [Prapagdee et al. 2008, Sharma et al. 2014].

Differentiated effect of antagonistic bacteria on antagonistic fungi was observed by Pięta and Patkowska [2003]. The results of their studies indicated the low sensitivity of Trichoderma koningii and Trichoderma viride to the presence of the tested bacteria. Inhibitory effect occurred in the case of common growth of fungi with $\mathrm{Ba}$ cillus sp., while the bacteria Erwinia sp., Pseudomonas sp. and Bacillus mycoides did not show any influence.

The strains of Streptomyces spp. were marked by intensive production of metabolites and their diffusion into the medium, which caused a con- siderable inhibition of the mycelium growth. The genus Streptomyces is known for production of many antibiotics, including fungicides. They synthesize more than 2000 antibiotics, which makes $82.5 \%$ of their production by actinomycetes [Dharmaraj 2010, Solecka 2013]. The ability to biosynthesize antibiotics is limited to very specific ecological niches. Micro-amounts of the antibiotics produced by actinomycetes in these habitats are big enough for them to act effectively to other microorganisms [Schrey and Tarkka 2008, Felice et al. 2014].

Marcinowska and Bis [1997] report that such cultivated plants as potato and flax affect negatively the growth of antagonistic actinomycetes. The results of the present studies do not confirm such a negative influence in case of potato. The study proved a high activity of actinomycetes derived from potato cultivation 
A

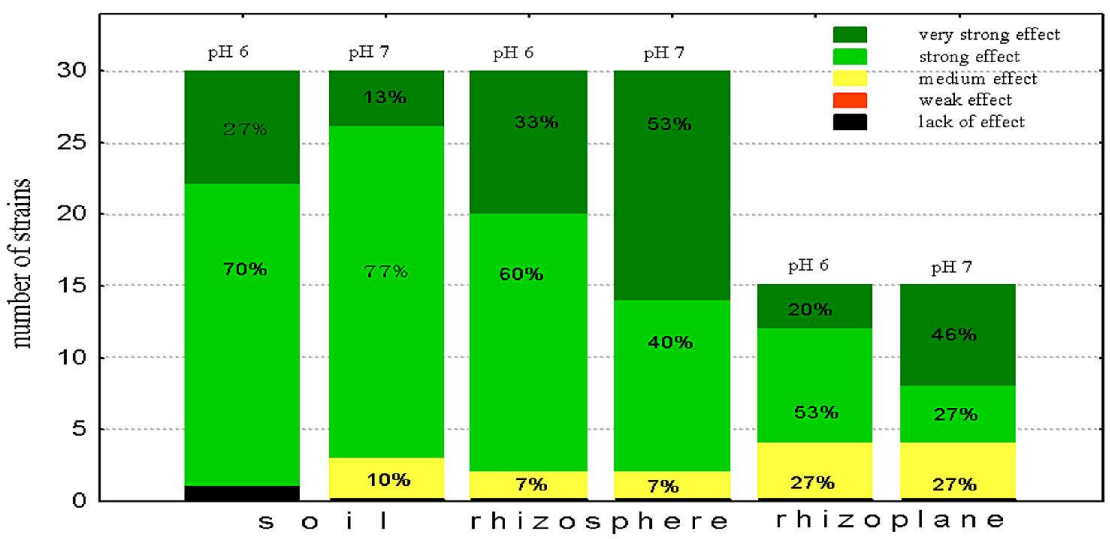

B

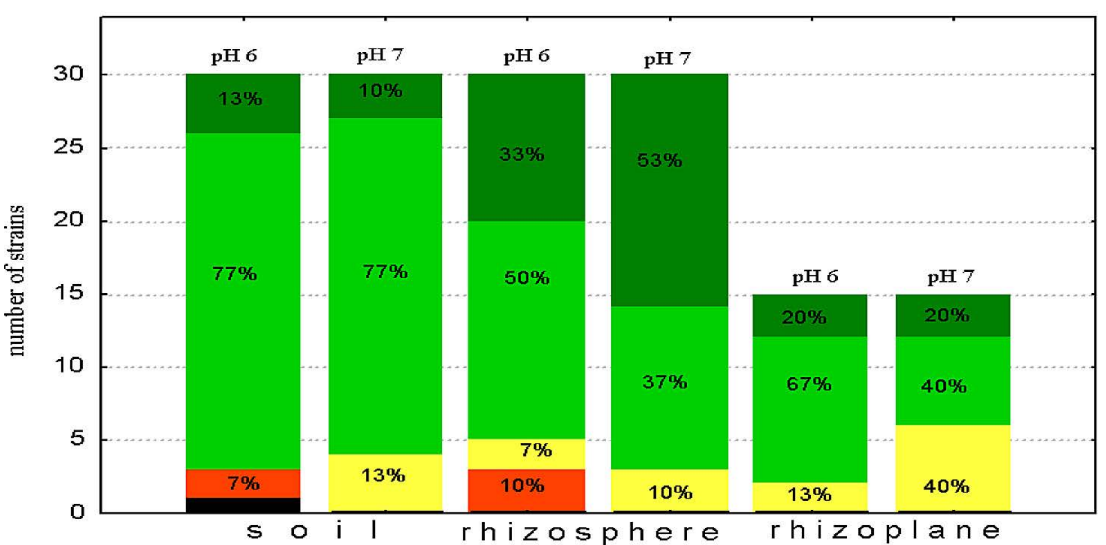

Figure 4. The number of Streptomyces spp. strains isolated from the soil, rhizosphere and rhizoplane of potato cultivated in ecological (A) and conventional (B) farming, and strength of their influence on the growth of Trichoderma koningii

in relation to T. koningii. Also in other studies a collection of actinomycetes showed antagonistic properties in relation to pathogenic fungi [Breza-Boruta et al. 2004].

Differentiation in the antagonistic activity of actinomycetes, according to the place of isolation, was recorded (soil beyond roots, rhizosphere and rhizoplane). The most active were the strains coming from potato rhizosphere. This can prove the favourable influence of potato roots excretions on the antibiotic activity of Streptomyces spp. [Pięta and Patkowska 2003, Mandic et al. 2011].

Of the tested population of Streptomyces spp., the strains isolated from the ecological farm showed a higher inhibitory strength in relation to $T$. koningii. Based on the obtained results, it may be suggested that more favourable conditions for the development of antagonistic actinomycetes can be found in the ecological farming than in a conventional system. There are not any comparisons concerning the activity of actinomycetes coming from different farming systems in the available bibliography.

Both the tested strains of Streptomyces spp. and the investigated fungus come from the same environment. The strong antagonism of the strains Stereptomyces in vitro is very likely to have an inhibitory effect on T. koningii in soil. We should regard physicochemical soil properties influencing the survival rate of potential antagonists. The most important of them are the structure of soil, temperature, $\mathrm{pH}$ value, the content of nutrients and the presence of toxic chemical compounds [Mandic et al. 2011, Felice et al. 2014]. According to Singh et al. [2014], species of the genus Trichoderma are not very sensitive to the effect of different environmental factors and develop in the wide range of temperatures and the medium $\mathrm{pH}$ values. From the present study it appears that T. koningii is sensitive to the change in $\mathrm{pH}$ value. Considerable differences in the fungal mycelium radius length were obtained both on the control plates and in 
a culture with actinomycetes. Significantly larger inhibition zones were indicated on the medium with $\mathrm{pH} 6$ than on that with $\mathrm{pH}$ 7, which has been confirmed by statistic calculations.

It is worth of notice, which was also observed by many investigators [Compant et al. 2005, Evangelista-Martínez 2014, Kamal and Sharma 2014], that it is very difficult to select different microorganisms for biological control. The most essential is that potential antagonists may be ecologically competitive in respect of the interaction between plants and pathogens both in soil and in phylosphere.

\section{CONCLUSIONS}

1. The actinomycetes of genus Streptomyces proved to be strong antagonists in relation to the fungus Trichoderma koningii. Of the strains limiting the growth of the fungal mycelium, the following strains isolated from potato rhizosphere were predominant: ZER-9, ZER-29, ZER-5, ZER-12, ZER-27, ZER-28, ZTR-10).

2. Significant influence of the medium $\mathrm{pH}$ on the growth of the mycelium of $T$. koningii was recorded both on the control plates and in the culture with actinomycetes. Statistically significantly larger inhibition zones were obtained on the medium with $\mathrm{pH} 6$ than on the medium with $\mathrm{pH} 7$.

3. Of the tested strains, the actinomycetes isolated from the ecological potato farming system showed stronger antagonistic properties, in comparison with the isolates derived from the conventional farming system.

4. From the point of view of biological control, strong inhibiting of growth of the fungus Trichoderma koningii (a potential mycoparasite of numerous plant pathogens) by so many strains of Streptomyces spp. is an undesirable phenomenon.

\section{REFERENCES}

1. Al-Askar A.A., Abdul Khair W.M., Rashad Y. 2011. In vitro antifungal activity of Streptomyces spororaveus RDS28 against some phytopathogenic fungi Afr. J. Agric. Res., 6(12), 2835-2842.

2. Bressan W., Figueiredo J.E. 2008. Efficacy and doseresponse relationship in biocontrol of Fusar- ium disease in maize by Streptomyces spp.. Eur. J. Plant Pathol., 120, 311-316.

3. Breza-Boruta B. 2013. Występowanie drobnoustrojów pektynolitycznych w glebie w systemie ekologicznym i konwencjonalnym. Polish Journal of Agronomy 15, 32-37.

4. Breza-Boruta B., Sadowski S. Paluszak. Z. 2004. Effect of Actinomycetes of Streptomyces genus isolated potato cultivation on the pathogenic fungus Rhizoctonia solani. Phytopathol. Pol., 31, 33-43.

5. Compant S., Duffy B., Nowak J., Clément C., Barka E.A. 2005. Use of growth-promoting bacteria for biocontrol of plant diseases: principles, mechanisms of action and future prospect. Appl. Environ. Microbiol., 71(9), 4951-4959.

6. Crawford D.L., Lynch J.M. Whipps J.M., Ousley M.A. 1993. Isolation and characterization of actinomycete antagonists of a fungal root pathogen. Appl. Environ. Microbiol., 59, 3899-3905.

7. Dharmaraj S. 2010. Marine Streptomyces as a novel source of bioactive substances. World J. Microbiol. Biotechnol., 26, 2123-2139.

8. Domsch K.H., Gams W., Anderson T.H. 1980. Compendium of soil fungi. Academic Press, London, England.

9. Evangelista-Martínez Z. 2014. Isolation and characterization of soil Streptomyces species as potential biological control agents against fungal plant pathogens. World J. Microbiol. Biotechnol., 30(5), 1639-1647.

10. Felice L., Jordan N.R., Dill-MackyR., Sheaffer C.C., Aldrich-Wolfe L., Huerd S.C., Kinkel L.L. 2014. Soil Streptomyces communities in a prairie establishment reflect interactions between soil edaphic characteristics and plant host. Plant and Soil, 386 (1-2), 89-98.

11. Gajera H.P., Bambharolia R.P., Patel S.V., Khatrani T.J., Goalkiya B.A. 2012. Antagonism of Trichoderma spp. against Macrophomina phaseolina: evaluation of coiling and cell wall degrading enzymatic activities. J. Plant Pathol. Microb., 3, 149-156.

12. Goodfellow M., Kämpfer P., Busse H.J.,Trujillo M.E., Suzuki K., Ludwig W., Whitman W.B. 2012 Bergey's Manual of Syst matic Bacteriology. 2nd Ed.,Vol. 5: The Actinobacteria. Part B., Springer Verlag, New York, 1455-1804.

13. Howell C.R. 2003. Mechanisms employed by Trichoderma species in the biological control of plant diseases: the history and evolution of current concepts. Plant Dis., 87, 4-1.

14. Kamal R., Sharma A.K. 2014. Control of Fusarium wilt using biological agent Streptomyces sp.CPP-53 isolated from compost with plant growth promoting effect on tomato under greenhouse condition. J. Microbiol. Antimicrob., 6 (6), 97-103. 
15. Kumar N., Singh R.K., Mishra S.K, Singh A.K., Pachouri U.C. 2010. Isolation and screening of soil Actinomycetes as a source of antibiotics active against bacteria. Int. J. Microbiol. Res., 2, 12-16.

16. Lee J.Y., Hwang B.K. 2002. Diversity of antifungal actinomycetes in various vegetative soils of Korea. Can J Microbiol. 48(5), 407-417.

17. Mandic L., Djukić D., Beatovic I., Jovovic Z., Pesakovic M., Stevovic V. 2011. Effect of different fertilizers on the microbial activity and productivity of soil under potato cultivation. Afr. J. Biotechnol., 10(36), 6954-6960.

18. Marcinowska K., Bis H., 1997. Występowanie promieniowców antybiotycznych w środowiskach glebowych intensywnych zmianowań specjalistycznych. W: Drobnoustroje w środowisku występowanie, aktywność i znaczenie. AR Kraków, 417-425.

19. Oskay M. 2009. Antifungal and antibacterial compounds from Streptomyces strains. Afr. J. Biotechnol., 8, 3007-3017.

20. Pięta D., Patkowska E. 2003. Antagonistic bacteria and fungi limiting potato infection by soil-borne pathogenic fungi. J. Plant Prot. Res., 43(2), 97-104.

21. Prapagdee B., Kuekulvong C., Mongkolsuk S. 2008. Antifungal potential of extracellular metabolites produced by Streptomyces hygroscopicus against phytopathogenic fungi. Int. J. Biol. Sci., 4(5), 330-337.
22. Reddy B.N., Saritha1 K.V., Hindumathi A. 2014. In vitro Screening for antagonistic potential of seven species of Trichoderma against different plant pathogenic fungi. Res. J. Biology 2, 29-36.

23. Schrey S.D., Tarkka M.T. 2008. Friends and foes: streptomycetes as modulators of plant disease and symbiosis. Antonie van Leeuwenhoek, 94, 11-19.

24. Sharma D., Mayilraj S., Manhas R.K. 2014. Streptomyces amritsarensis sp. nov., exhibiting broadspectrum antimicrobial activity. Antonie Van Leeuwenhoek, 4(5), 943-949.

25. Singh A., Shahid M., Srivastava M., Pandey S., Sharma A., Kumar V. 2014. Optimal physical parameters for growth of Trichoderma species at varying $\mathrm{pH}$, temperature and agitation. Virology and Mycology, 3(1), 127-134.

26. Solecka J., Ziemska J., Rajnisz A., Laskowska A., Guśpiel A. 2013. Promieniowce - występowanie i wytwarzanie związków biologicznie czynnych. Post. Mikrobiol., 52 (1), 83-91.

27. Świerczyńska I., Korbas M., Horoszkiewicz-Janka J., Danielewicz J. 2011. Antagonistyczne oddziaływanie Trichoderma viride na patogeny z rodzaju Fusarium w obecności biopreparatów. J. Res. Appl. Agric. Engng., 56(4) 157-160.

28. Williams S.T., Davies F.L. 1965. Use of antibiotics for selective isolation and enumeration of Actinomycetes in soil. J. Gen. Microbiol., 38, 251-261. 